\title{
Pretreatment Cognitive Profile Likely to Benefit from Donepezil Treatment in Dementia with Lewy Bodies: Pooled Analyses of Two Randomized Controlled Trials
}

\author{
Etsuro Mori $^{a}$ Manabu Ikedab,c Masaki Nakagawad Hideaki Miyagishid ${ }^{d}$ \\ Kenji Kosaka ${ }^{e}$ \\ ${ }^{a}$ Department of Behavioral Neurology and Cognitive Neuroscience, Tohoku University \\ Graduate School of Medicine, Sendai, b ${ }^{b}$ epartment of Neuropsychiatry, Faculty of Life \\ Sciences, Kumamoto University, Kumamoto, 'Department of Psychiatry, Osaka University \\ School of Medicine, Osaka, 'Eisai Co., Ltd., Tokyo, and e Department of Psychiatry, \\ Yokohama City University School of Medicine, Yokohama, Japan
}

\author{
Key Words \\ Dementia · Lewy bodies · Cholinesterase inhibitors · Cognitive function · Mini-Mental State \\ Examination
}

\begin{abstract}
Background/Aims: Based on Mini-Mental State Examination (MMSE) subitem scores, in dementia with Lewy bodies (DLB), we aimed to delineate features of cognitive impairment, identify cognitive domains improved by donepezil, and define a pretreatment cognitive profile likely to benefit from donepezil. Methods: Pooled data were used from two randomized controlled trials of donepezil in DLB $(n=235)$. Baseline MMSE subitem scores were calculated for all patients. Mean changes in subitem scores at week 12 were compared between the placebo and the active group. Finally, the subgroup identification based on differential effect search (SIDES) method was applied. Results: Baseline subitem scores were relatively low for serial 7's, delayed recall, and copying. Significant improvement by donepezil was found for orientation, serial 7's, repetition, 3-step command, and copying. The subgroup with pretreatment scores of serial 7's $=1,2$, or 3 , delayed recall $\geq 1$, and copying $=0$ were the best responders. MMSE change in subgroups increased as more of these three conditions were fulfilled. Conclusion: Cognitive domains characteristically impaired in DLB are particularly improved by donepezil. The number of fulfilled conditions for serial 7's $=1,2$, or 3 , delayed recall $\geq 1$, and copying $=0$ (likely to benefit score) may predict the response to donepezil in DLB patients.


Mori et al.: Pretreatment Cognitive Profile Likely to Benefit from Donepezil Treatment in Dementia with Lewy Bodies: Pooled Analyses of Two Randomized Controlled Trials

\section{Introduction}

Dementia with Lewy bodies (DLB) is the second most common type of degenerative dementia in the elderly after Alzheimer's disease (AD) [1]. The clinical features of DLB include neuropsychiatric symptoms, parkinsonism, and cognitive impairment [2]. Cholinergic neurotransmission is more defective in patients with DLB than in those with AD [3]. Moreover, cholinergic loss in DLB affects both brainstem and basal forebrain presynaptic nuclei while preserving postsynaptic cortical muscarinic receptors [4]. Thus, cholinesterase inhibitors (ChEIs) have been considered to be more effective for DLB, with galantamine, rivastigmine, and donepezil shown to exert favorable effects in clinical studies [5-10].

In clinical trials as well as clinical practice, cognitive function in DLB patients is often assessed using the Mini-Mental State Examination (MMSE) [5-10]. The MMSE was originally developed as a screening test for cognitive impairment [11]. It readily evaluates overall cognitive function in only about $10 \mathrm{~min}$ [11], and is therefore widely used for assessment of cognitive impairment in dementia patients in clinical practice and studies worldwide. The test consists of 11 subitems, with each subitem evaluating different cognitive domains including orientation, memory, attention, and construction. Cognitive impairment in DLB is characterized by deficits in attention, executive function, and visual perception [1], which may be reflected in each MMSE subitem score. Examining treatment changes in subitem scores may identify cognitive domains that are particularly improved by the treatment.

In our previous phase 2 and 3 donepezil trials for DLB, we used the MMSE to assess cognitive function. We found significantly improved cognitive function in patients administered donepezil compared with those given a placebo, with the improvement lasting for at least 1 year [12-15]. Here, based on MMSE scores, we further delineated features of cognitive impairment and identified cognitive domains that are likely improved by donepezil in DLB patients. Furthermore, we identified a pretreatment cognitive profile in individuals who would likely benefit from donepezil treatment. As the MMSE is widely used in clinical practice, such factors, if any, would be useful to predict the response to donepezil and the prognosis of individual patients.

\section{Materials and Methods}

\section{Data Analyzed}

This analysis used pooled data obtained from two randomized, double-blind, placebo-controlled trials (RCTs) of donepezil treatment for DLB which had been conducted in Japan. A 12-week phase 2 exploratory RCT was conducted from 2007 to investigate the efficacy and safety of donepezil at 3, 5, and $10 \mathrm{mg} /$ day (ClinicalTrials.gov reference: NCT00543855). Subsequently, a confirmatory phase 3 trial, including a 16-week RCT phase, was conducted from 2011 to confirm the superiority of donepezil at 5 and $10 \mathrm{mg} /$ day for 12 weeks over placebo (ClinicalTrials.gov reference: NCT01278407). In both studies, the 5- and 10-mg groups began treatment at $3 \mathrm{mg} /$ day, with the dose increased to $5 \mathrm{mg}$ at week 2 and then to $10 \mathrm{mg}$ at week 6 (in only the 10-mg group). The results of these RCTs have been published previously [12,14]. Each study was performed in accordance with the principles of the Declaration of Helsinki. Before initiating the study procedures, written informed consent was obtained from the patient (if at all possible) and his/her primary family member.

The inclusion and exclusion criteria were almost identical for both RCTs. The inclusion criteria were: patients aged $\geq 50$ years with probable DLB that fulfilled the consensus diagnostic criteria [2], having mild to severe dementia (10-26 points on MMSE and Clinical Dementia Rating score $\geq 0.5$ ) and having behavioral and psychiatric symptoms [Neuropsychiatric Inventory Plus (NPI-plus) (12 items: original 10 NPI items with sleep $[16,17]$ and cognitive fluctuation reported as Cognitive Fluctuation Inventory $[8,18]) \geq 8$ and NPI-2 (hallucinations and cognitive fluctuation [12], only at phase 3) $\geq 1$ ]. Outpatients were recruited from psychiatric or neurological specialty centers throughout Japan [19]. The diagnosis of each patient was made by investigators from each center and validated after discussion by the central committee. 


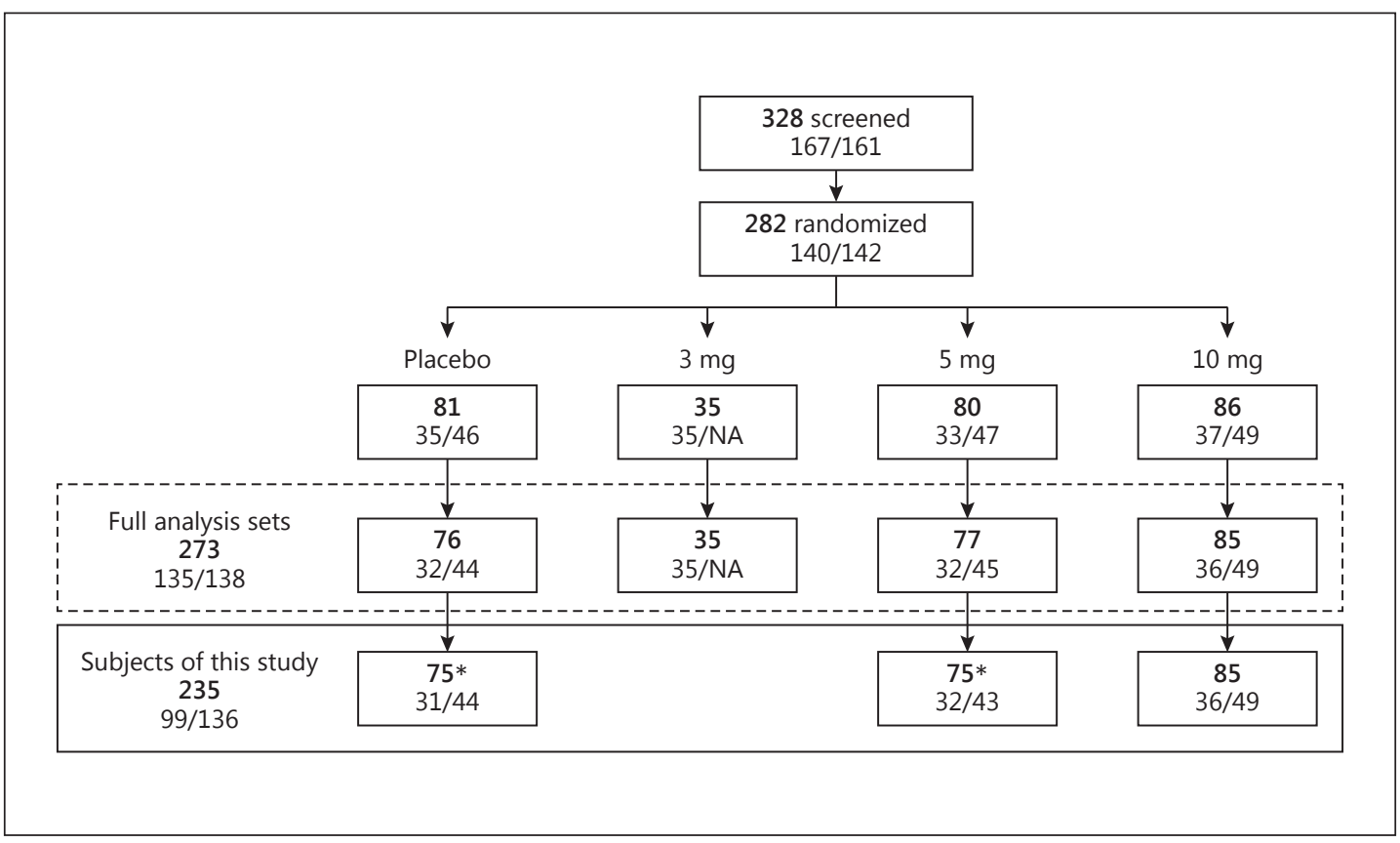

Fig. 1. Patient disposition in two RCTs. Bold indicates the total number of subjects in two trials. Left/right indicates the number of subjects in phase 2/phase 3 trials. * Patients without MMSE data were excluded.

The exclusion criteria included Parkinson's disease diagnosed at least 1 year prior to dementia onset, focal vascular lesions or multiple infarctions on MRI or CT that might cause cognitive impairment, other neurological or psychiatric diseases, complications or a history of severe gastrointestinal ulcers, severe asthma or obstructive pulmonary disease, systolic hypotension ( $<90 \mathrm{~mm} \mathrm{Hg}$ ), bradycardia ( $<50 \mathrm{bpm})$, sick sinus syndrome, atrial or atrioventricular conduction block, QT interval prolongation ( $\geq 450 \mathrm{~ms}$ ), severe parkinsonism (Hoehn and Yahr stage $\geq 4$ ) [20], and treatment with ChEIs or any investigational drug within 3 months prior to screening. Furthermore, except for stable doses of levodopa and dopamine agonists, ChEIs, antipsychotics, and anti-Parkinson drugs were not allowed during the trials.

From the full analysis set of these two RCTs $(n=273)$, the data of patients with MMSE scores at baseline and at least one post-baseline visit in the placebo, 5-mg, and 10-mg groups were incorporated into this analysis (fig. 1). The data of the 3-mg arm $(n=35)$ of the phase 2 trial was not used as there was no significant difference from the placebo arm after adjusting for multiple comparisons; furthermore, 3 mg was not tested in the phase 3 trial. As a clear dose-response relationship between the 5- and 10-mg groups was not noted in the two trials, both dose groups were combined into a single group in the present analysis $(\mathrm{n}=235$; incorporating 99 from phase 2 and 136 from phase 3).

\section{MMSE Assessment}

In both RCTs, the MMSE was used to assess cognitive function. MMSE scores ranging from 0 to 30 encompassed the following 11 subitems: orientation for time ( 5 points), orientation for place ( 5 points), immediate recall ( 3 points), attention/calculation ( 5 points), delayed recall ( 3 points), naming ( 2 points), repetition ( 1 point), 3-step command ( 3 points), reading (1 point), writing (1 point), and copying (1 point) [11]. In both trials, only the serial 7's test was applied and the spelling backwards substitution not allowed, as the two tests are not equivalent: the former produces lower scores than the latter [21], has merit in terms of variability, internal consistency, and measurement error [22], and is not affected by the orthographic systems of different languages. Above all, to detect serial changes in longitudinal studies, consistent use of the test is desirable.

\section{Statistical Analysis}

The patients were divided into two groups: the placebo group and the active drug group (which was administered 5 or $10 \mathrm{mg}$ donepezil). For all patients, the mean score of each MMSE subitem at baseline was 
Mori et al.: Pretreatment Cognitive Profile Likely to Benefit from Donepezil Treatment in Dementia with Lewy Bodies: Pooled Analyses of Two Randomized Controlled Trials

Table 1. Patient demographics and clinical characteristics at baseline

\begin{tabular}{lccc}
\hline & $\begin{array}{l}\text { All } \\
(\mathrm{n}=235)\end{array}$ & $\begin{array}{l}\text { Placebo group } \\
(\mathrm{n}=75)\end{array}$ & $\begin{array}{l}\text { Active group } \\
(\mathrm{n}=160)\end{array}$ \\
\hline Sex & & & \\
$\quad$ Male & $86(36.6 \%)$ & $26(34.7 \%)$ & $60(37.5 \%)$ \\
$\quad$ Female & $149(63.4 \%)$ & $49(65.3 \%)$ & $100(62.5 \%)$ \\
Age, years & $78.1 \pm 6.0$ & $77.7 \pm 5.5$ & $78.2 \pm 6.2$ \\
Weight, kg & $49.5 \pm 9.8$ & $49.3 \pm 10.0$ & $49.6 \pm 9.8$ \\
Disease duration, years & $2.2 \pm 1.9$ & $2.4 \pm 2.3$ & $2.2 \pm 1.8$ \\
Core features & & & \\
$\quad$ Cognitive fluctuation & $220(93.6 \%)$ & $70(93.3 \%)$ & $150(93.8 \%)$ \\
$\quad$ Visual hallucination & $201(85.5 \%)$ & $69(92.0 \%)$ & $132(82.5 \%)$ \\
$\quad$ Parkinsonism & $203(86.4 \%)$ & $65(86.7 \%)$ & $138(86.3 \%)$ \\
MMSE & $20.0 \pm 4.5$ & $19.5 \pm 4.5$ & $20.2 \pm 4.4$ \\
NPI-10 & $18.0 \pm 12.7$ & $19.5 \pm 12.8$ & $17.3 \pm 12.7$ \\
NPI-2 & $7.0 \pm 4.6$ & $6.8 \pm 4.2$ & $7.2 \pm 4.8$ \\
UPDRS part III & $20.2 \pm 11.6$ & $21.2 \pm 11.4$ & $19.7 \pm 11.7$ \\
\hline
\end{tabular}

Values are expressed as mean $\pm \mathrm{SD}$ or $\mathrm{n}(\%)$.

UPDRS = Unified Parkinson's disease rating scale.

calculated. As the full score of each MMSE subitem varies, a proportional score was obtained by dividing the obtained score by the highest possible score, thereby allowing direct comparison of performance between subitems. Mean MMSE change in total score and individual item scores from baseline to week 12 were calculated in each treatment group. If the MMSE score at week 12 was unavailable, a value from the final evaluation point was imputed using a last observation carried forward method. Intergroup comparisons of mean change were performed by analysis of covariance, with baseline values as the covariate. These statistical analyses were performed with a two-tailed 0.05 significance level using SAS for Windows, version 9.3 (SAS Institute Inc., Cary, N.C., USA).

Subsequently, the subgroup identification based on differential effect search (SIDES) method [23] was applied to identify subgroups defined by baseline MMSE subitem score profile, which in terms of total MMSE score likely improved at week 12 with donepezil treatment. A common approach to identify subgroups is regression-based analysis of subsets (via models with main effects and interactions), in which subgroups are identified based on significant interaction terms. However, this approach usually lacks statistical power and has difficulties in specifying interaction terms and covariate cutoffs. The SIDES method, which is flexible in terms of search criterion, can focus on the treatment effect and therefore directly search for predictive covariates. Furthermore, this method can search for subgroups with a large differential effect relative to the overall population. There are three steps in the SIDES method. In the first step, subgroups with an enhanced treatment effect are identified recursively under the constraints of a maximum number of covariates defining subgroups and a minimal sample size. In the second step, only subgroups in which the treatment effect is below a prespecified threshold value are retained. In the third step, a multiplicity adjustment is applied to correct $\mathrm{p}$ values for the treatment effect within the identified subgroups. In the present analysis, the splitting criterion was set as the differential, and the minimal sample size per treatment arm in a subgroup as 20 . The default settings in the SIDEScreen Excel Macro provided by Lipkovich and Dmitrienko [24] were used for the other criteria.

\section{Results}

Baseline Patient Characteristics

The demographics and clinical characteristics of all 235 patients at baseline are summarized in table 1 . There were no notable differences between the placebo and the active drug 
Dementia

Fig. 2. Mean proportional MMSE subitem scores at baseline in overall patients. Proportional scores ranging from 0 to 1 were calculated by dividing each MMSE item score by the full item score. Error bars indicate SD.

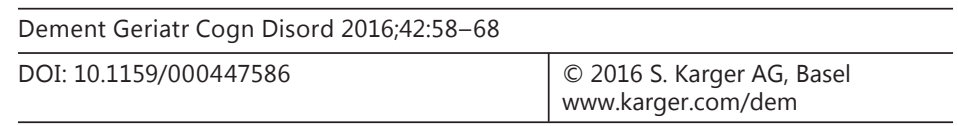

Mori et al.: Pretreatment Cognitive Profile Likely to Benefit from Donepezil Treatment in Dementia with Lewy Bodies: Pooled Analyses of Two Randomized Controlled Trials

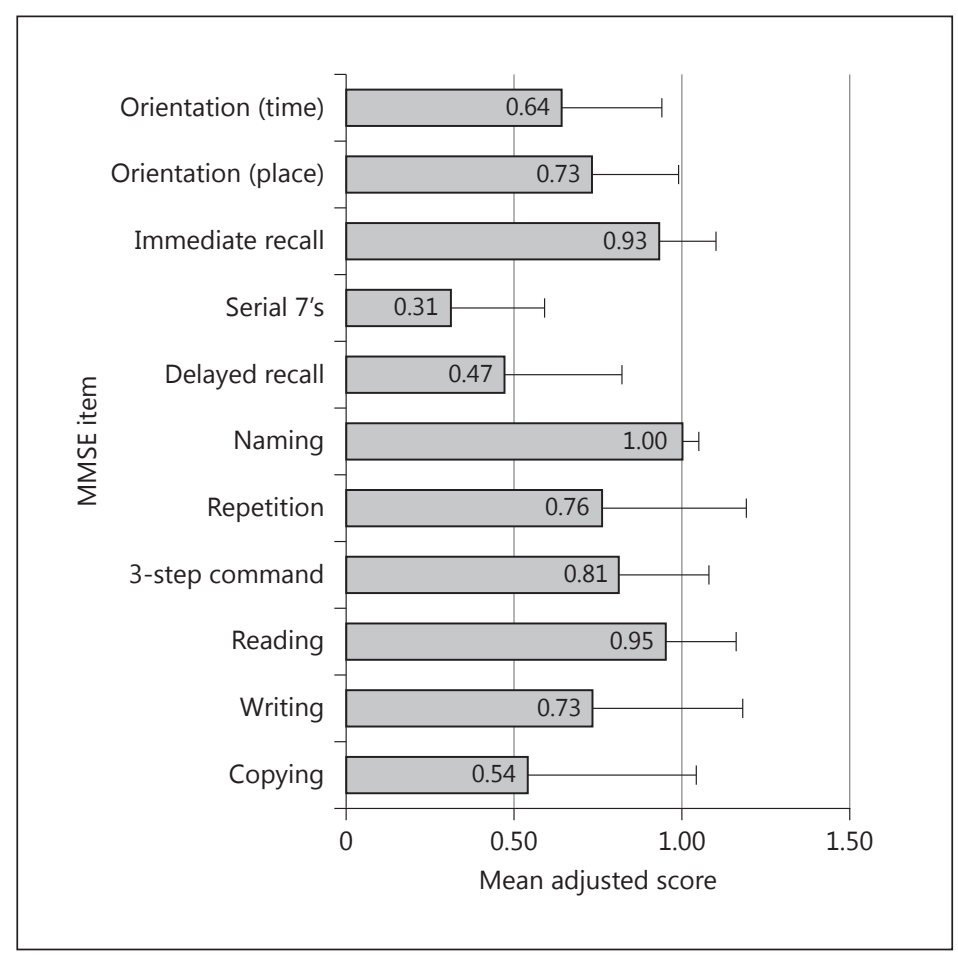

group. Overall, females accounted for $63.4 \%$. Mean age ( \pm standard deviation, SD) was $78.1 \pm$ 6.0 , and all but 2 patients were 65 years or older. The mean MMSE score $( \pm$ SD) was $20.0 \pm$ 4.5 .

\section{Baseline MMSE Subitem Score Profiles}

The mean proportional scores for MMSE subitems at baseline in the overall patient group are shown in figure 2 . The proportional scores for the following items were relatively low: serial 7's $(0.31 \pm 0.28)$, delayed recall $(0.47 \pm 0.35)$, and copying $(0.54 \pm 0.50)$. In contrast, the scores for immediate recall $(0.93 \pm 0.17)$, naming $(1.00 \pm 0.05)$, and reading $(0.95 \pm 0.21)$ were high.

\section{Changes in MMSE Subitem Scores from Baseline to Week 12}

The mean changes in total MMSE score and in each subitem score from baseline to week 12 are shown in table 2 . The mean change $( \pm$ SD) in total MMSE score was $0.20 \pm 2.93$ in the placebo group and $2.19 \pm 3.25$ in the active drug group, with a significant difference between groups $(\mathrm{p}<0.001)$. The mean change in the 5 - and 10 -mg groups was comparable $(2.27 \pm 3.46$ and $2.12 \pm 3.06$, respectively). There were also significant intergroup (placebo versus active) differences in mean change of orientation for time $(p<0.001)$, orientation for place $(p=$ $0.026)$, serial 7's $(p=0.022)$, repetition $(p=0.045), 3$-step command $(p=0.018)$, and copying $(\mathrm{p}=0.030)$.

\section{Subgroups Likely to Benefit from Donepezil Treatment in Terms of MMSE Score}

The SIDES method selected the following three covariates: delayed recall, serial 7's, and copying. Four subgroups, namely (1) serial 7's $\geq 1$ and delayed recall $\geq 1$, (2) serial 7's $\geq 1$ and copying $=0$, (3) delayed recall $\geq 1$ and copying $=0$, and (4) serial 7's $\leq 3$, delayed recall $\geq 1$, and copying $=0$, were identified as the best responders, in which large changes in total MMSE 
Dementia

Cognitive Disorders
Dement Geriatr Cogn Disord 2016:42:58-68

DOI: $10.1159 / 000447586$

Mori et al.: Pretreatment Cognitive Profile Likely to Benefit from Donepezil Treatment in Dementia with Lewy Bodies: Pooled Analyses of Two Randomized Controlled Trials

Table 2. Mean changes in total MMSE score and in each subitem score from baseline to week 12 (last observation carried forward method)

\begin{tabular}{lccc}
\hline MMSE item & $\begin{array}{l}\text { Placebo group } \\
(\mathrm{n}=75)\end{array}$ & $\begin{array}{c}\text { Active group } \\
(\mathrm{n}=160)\end{array}$ & $\mathrm{p} \mathrm{value}^{\mathrm{a}}$ \\
\hline Total score & $0.20 \pm 2.93$ & $2.19 \pm 3.25$ & $<0.001$ \\
Orientation for time & $-0.21 \pm 1.30$ & $0.41 \pm 1.42$ & $<0.001$ \\
Orientation for place & $0.04 \pm 0.91$ & $0.28 \pm 1.02$ & 0.026 \\
Immediate recall & $-0.01 \pm 0.45$ & $0.06 \pm 0.47$ & 0.277 \\
Serial 7's & $0.23 \pm 1.37$ & $0.72 \pm 1.68$ & 0.022 \\
Delayed recall & $0.16 \pm 1.03$ & $0.32 \pm 1.04$ & 0.152 \\
Naming & $0.00 \pm 0.16$ & $0.00 \pm 0.11$ & 0.581 \\
Repetition & $-0.07 \pm 0.53$ & $0.03 \pm 0.47$ & 0.045 \\
3-step command & $0.13 \pm 0.93$ & $0.26 \pm 0.80$ & 0.018 \\
Reading & $0.01 \pm 0.26$ & $-0.03 \pm 0.22$ & 0.625 \\
Writing & $-0.08 \pm 0.36$ & $0.02 \pm 0.40$ & 0.097 \\
Copying & $0.00 \pm 0.37$ & $0.11 \pm 0.50$ & 0.030 \\
\hline
\end{tabular}

Values are expressed as mean $\pm \mathrm{SD}$.

${ }^{a}$ Analysis of covariance, with the treatment group as the factor and baseline values as the covariate.

Table 3. SIDES results

\begin{tabular}{|c|c|c|c|c|c|}
\hline Selected subgroup & Group & $\mathrm{n}$ & $\begin{array}{l}\text { Mean change } \\
\text { in total MMSE }\end{array}$ & $\begin{array}{l}\text { Effect } \\
\text { size }\end{array}$ & p value ${ }^{a}$ \\
\hline All subjects & $\begin{array}{l}\mathrm{A} \\
\mathrm{P}\end{array}$ & $\begin{array}{r}160 \\
75\end{array}$ & $\begin{array}{l}2.2 \\
0.2\end{array}$ & 0.631 & $<0.001$ \\
\hline Serial 7's $\geq 1$ and delayed recall $\geq 1$ & $\begin{array}{l}\mathrm{A} \\
\mathrm{P}\end{array}$ & $\begin{array}{r}103 \\
38\end{array}$ & $\begin{array}{r}2.4 \\
-0.7 \\
\end{array}$ & 1.030 & $<0.001$ \\
\hline Serial 7's $\geq 1$ and copying $=0$ & $\begin{array}{l}\mathrm{A} \\
\mathrm{P}\end{array}$ & $\begin{array}{l}45 \\
25\end{array}$ & $\begin{array}{l}3.6 \\
0.0\end{array}$ & 1.197 & $<0.001$ \\
\hline Delayed recall $\geq 1$ and copying $=0$ & $\begin{array}{l}\mathrm{A} \\
\mathrm{P}\end{array}$ & $\begin{array}{l}58 \\
24\end{array}$ & $\begin{array}{r}3.1 \\
-0.4\end{array}$ & 1.164 & $<0.001$ \\
\hline $\begin{array}{l}\text { Serial 7's } \leq 3 \text { and delayed recall } \geq 1 \\
\text { and copying }=0\end{array}$ & $\begin{array}{l}\mathrm{A} \\
\mathrm{P}\end{array}$ & $\begin{array}{l}57 \\
20\end{array}$ & $\begin{array}{r}3.1 \\
-0.2\end{array}$ & 1.114 & $<0.001$ \\
\hline
\end{tabular}

score from baseline to on-treatment were detected in the active drug group compared with the placebo group (table 3 ). In the population included within all four subgroups (i.e., serial 7 's $=1,2$, or 3, delayed recall $\geq 1$, and copying $=0$ ), the mean total MMSE score improved from 19.6 to 23.1 , with a mean change of $3.5 \pm 3.1$ in the active drug group $(n=36)$ (fig. 3), while the mean change for the overall population was $2.19 \pm 3.25$. According to the definition of the number of conditions fulfilled among the following: serial 7's $=1,2$ or 3 , delayed recall $\geq 1$, and copying $=0$ as the likely to benefit (LTB) score, the mean change of total MMSE score in the active group was $3.5 \pm 3.1$ for LTB score $=3,2.2 \pm 3.2$ for LTB score $=2,1.8 \pm 2.4$ for LTB score $=1$, and $-2.1 \pm 3.7$ for LTB score $=0$ (fig. 4 ). The Jonckheere-Terpstra trend test showed 
Dementia

Fig. 3. Mean change in total MMSE score in the population included within all the four subgroups identified by the SIDES method. LOCF = Last observation carried forward method. Error bars indicate SD. The population included in all the four subgroups: patients with serial 7's scores of 1-3, delayed recall scores of $\geq 1$, and copying scores of 0 .

Fig. 4. Mean change in total MMSE score by LTB score. Error bars indicate SD. LTB score (0-3) represents the number of fulfilled conditions among the following conditions: (1) serial 7's $=1,2$, or 3 , (2) delayed recall $\geq 1$, and (3) copying $=0$.

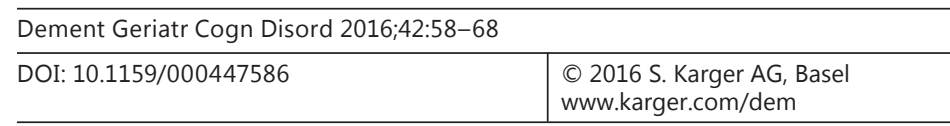

Mori et al.: Pretreatment Cognitive Profile Likely to Benefit from Donepezil Treatment in Dementia with Lewy Bodies: Pooled Analyses of Two Randomized Controlled Trials
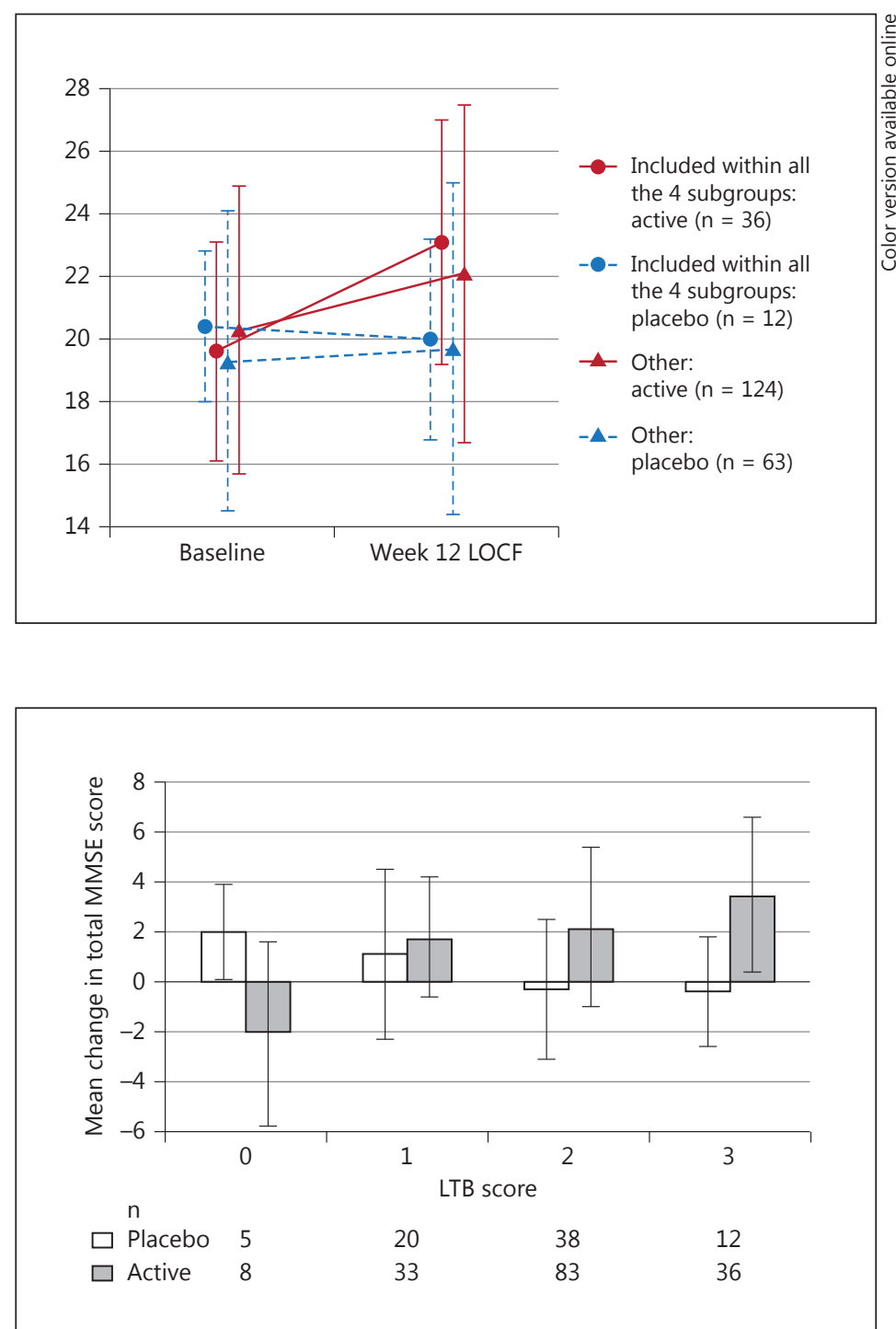

a statistically significant trend $(p=0.001)$ of higher LTB scores with greater total MMSE score change. Furthermore, the Cochran-Armitage trend test showed a statistically significant trend $(\mathrm{p}=0.001)$ between LTB score and a proportion of individuals whose MMSE improved by 3 points or more $(58 \%$ for LTB score $=3,49 \%$ for LTB score $=2,42 \%$ for LTB score $=1$, and $0 \%$ for LTB score $=0$ ).

\section{Discussion}

Using pooled data from two donepezil RCTs, we analyzed the pattern of MMSE subitem scores in DLB patients likely to respond to donepezil in terms of cognitive impairment. We found evidence for a specific MMSE profile that may indicate a favorable cognitive response to donepezil treatment in DLB patients.

First of all, the subitem scores of serial 7's, delayed recall, and copying were found to be disproportionally reduced compared with other domains. This is similar to a previous study 
Dementia

Cognitive Disorders

\begin{tabular}{l|l}
\hline Dement Geriatr Cogn Disord 2016;42:58-68 \\
\hline DOI: 10.1159/000447586 & $\begin{array}{l}\text { (c) 2016 S. Karger AG, Basel } \\
\text { www.karger.com/dem }\end{array}$ \\
\hline
\end{tabular}

Mori et al.: Pretreatment Cognitive Profile Likely to Benefit from Donepezil Treatment in Dementia with Lewy Bodies: Pooled Analyses of Two Randomized Controlled Trials

[25], which suggests that in terms of cognitive impairment, the present study population is likely to be representative of DLB patients. Relatively low MMSE subitem scores for serial 7's and copying may reflect cognitive impairment characteristics of DLB, with greater deficits in attention and visual perception/construction [2]. Additionally, the delayed recall score was disproportionally low among the subitems. However, compared with AD patients, the performance of DLB patients appears relatively good, as the subitem score $(1.41 \pm 1.04)$ indicates that patients successfully recalled approximately half of the three words.

Using the SIDES approach, we found that patients with serial 7's scores of 1-3, delayed recall scores of $\geq 1$, and copying scores of 0 particularly showed cognitive improvement by donepezil treatment. Considering the findings discussed above, donepezil is likely to be more effective in the subgroup with a typical DLB cognitive impairment pattern. This is consistent with the finding that DLB patients who do not show imaging features of a coexistent AD-related pathology are more likely to cognitively improve with ChEI treatment [26]. In the group of patients who met more of the conditions for serial 7's $=1,2$, or 3 , delayed recall $\geq 1$, and copying $=0$, the mean change in total MMSE score was larger (fig. 4). The LTB score may predict the response to donepezil and the prognosis of the individual patient. Conversely, the subgroup of patients with serial 7's or delayed recall scores of 0 is unlikely to benefit from donepezil. This subgroup includes those with an advanced stage of DLB or with concomitant AD pathology. Therefore, in any case, early initiation of donepezil treatment is recommended.

With regard to the effect of donepezil on different cognitive domains, significant improvements were shown for the following items: orientation for time and place, serial 7's, repetition, 3-step command, and copying. These items supposedly relate to measurements of attention, working memory, and visual perception, which are characteristically defective in DLB patients [2, 27]. The effect of donepezil on these cognitive domains has also been demonstrated by other specific neuropsychological tests in our phase 2 trial, including the Wechsler Memory Scale-Revised (WMS-R) attention/concentration subscale and the Wechsler Adult Intelligence Scale (WAIS) symbol digit modality subscale [12]. These findings indicate that donepezil particularly works on cognitive impairments that are characteristic of DLB. However, it should be noted that our findings do not necessarily mean that donepezil has no positive effect on other cognitive functions (e.g., memory). Indeed, due to the smallest range of subitem MMSE scores, the change might not be detected by a floor or ceiling effect. Rather, our analysis shows that donepezil has more favorable effects on cognitive impairment as a whole, as total MMSE score and most of the subitem scores show significant improvements. Moreover, donepezil was found to be associated with improved cognitive fluctuation [12]. Thus, in addition to improved basic cognitive function, reduction of depth and frequency of cognitive dips may lower the probability that a patient is in the cognitive dip phase when the MMSE is administered, thereby resulting in an increased mean score.

We cannot conclude that our findings are specific for DLB, as similar analyses have not been performed in $\mathrm{AD}$ populations. In previous AD trials, a considerable number of subjects meeting the criteria for DLB were reportedly included $[28,29]$. Although a similar trend as in our present DLB study might be shown in such populations, this would not necessarily mean that it is the case in $\mathrm{AD}$ patients.

There are some limitations to our analysis. First, the present study is exploratory in nature, therefore the sample size was not predefined and no adjustment for multiplicity was applied. Thus, our statistical test results should be interpreted with caution, and further confirmatory studies are needed to reinforce our findings. Furthermore, it should be noted that our study is based on data from 12-week RCT phases. Considering our findings as well as the aforementioned characteristics of DLB, longer-term studies are indicated to further 
delineate the long-term efficacy of donepezil in relation to changes in individual MMSE item scores along with disease progression. There are also limitations inherent in the cognitive measurements: only the MMSE was considered as predictive and outcome measures, which is neuropsychologically insufficient but practically relevant, and changes in MMSE scores may include a practice effect, although differences between the donepezil and placebo groups suggest that a substantial part of the changes is likely attributable to the effect of donepezil. Additionally, since serial 7's alone was used as the test for attention in our trials, the findings cannot be applied to the spelling backwards score. There are also methodological limitations inherent in our selection of subjects: incorporation of behavioral and psychiatric symptoms with a cutoff of NPI-plus $\geq 8$ and NPI- $2 \geq 1$ in the inclusion criteria will exclude DLB patients without neuropsychiatric issues. Furthermore, the original consensus diagnostic criteria rather than the revised criteria [30] were used because of the unavailability of dopamine transporter imaging in Japan when the studies were conducted, as well as unfeasibility of polysomnographic confirmation of REM sleep behavior disorder. These may somewhat limit the generalizability of our findings, in return raising diagnostic specificity. Finally, the dose of donepezil was not considered here, although plasma donepezil concentration was shown to correlate positively with change in MMSE score [31].

In conclusion, donepezil treatment in DLB patients positively affects performance on the following MMSE items: orientation for time and place, serial 7's, repetition, 3-step command, and copying, which are supposedly related to attention, working memory, and visual perception. In terms of cognition defined as total MMSE score, DLB patients that fulfill the following three conditions of baseline MMSE subitem scores are likely to benefit from donepezil: serial 7's $=1,2$, or 3, delayed recall $\geq 1$, and copying $=0$. Response to donepezil increases as the number of fulfilled conditions (LTB score) increases.

\section{Acknowledgments}

We thank all the patients and caregivers for their participation in the study, all the investigators and their site staff for their contributions, Clinical Study Support, Inc., for their editorial assistance in preparing the manuscript, and the Eisai study team for their assistance. The studies and analyses were sponsored by Eisai Co., Ltd. (Tokyo, Japan). The sponsor was involved in the study design, data collection and analysis, as well as review of the manuscript.

\section{Disclosure Statement}

E. Mori received personal fees from Eisai during the conduct of the studies, grants and personal fees from Eisai, Daiichi Sankyo, and FUJIFILM RI, and personal fees from Janssen, Johnson \& Johnson, Lundbeck, Novartis, Ono, Nihon Medi-Physics, and Medtronic outside the submitted work. M. Ikeda received personal fees from Eisai during the conduct of the studies, grants and personal fees from Daiichi Sankyo, Eisai, FUJIFILM RI, Janssen, Nihon Medi-Physics, Novartis, Pfizer, Takeda, and Tsumura, and personal fees from MSD, Ono, and Yoshitomi outside the submitted work. All grants stated above were for the authors' departments, and the authors received them as the directors of their department. K. Kosaka received personal fees from Eisai during the conduct of the studies, and personal fees from Tsumura, Eisai, Janssen, FUJIFILM RI, Novartis, Nihon Medi-Physics, Daiichi Sankyo, Ono, Otsuka, and Dainippon Sumitomo outside the submitted work. M. Nakagawa and H. Miyagishi are employees of Eisai. 
Mori et al.: Pretreatment Cognitive Profile Likely to Benefit from Donepezil Treatment in Dementia with Lewy Bodies: Pooled Analyses of Two Randomized Controlled Trials

\section{References}

1 McKeith I, Mintzer J, Aarsland D, Burn D, Chiu H, Cohen-Mansfield J, Dickson D, Dubois B, Duda JE, Feldman H, Gauthier S, Halliday G, Lawlor B, Lippa C, Lopez OL, Carlos Machado J, O’Brien J, Playfer J, Reid W; International Psychogeriatric Association Expert Meeting on DLB: Dementia with Lewy bodies. Lancet Neurol 2004;3: 19-28.

2 McKeith IG, Galasko D, Kosaka K, Perry EK, Dickson DW, Hansen LA, Salmon DP, Lowe J, Mirra SS, Byrne EJ, Lennox G, Quinn NP, Edwardson JA, Ince PG, Bergeron C, Burns A, Miller BL, Lovestone S, Collerton D, Jansen EN, Ballard C, de Vos RA, Wilcock GK, Jellinger KA, Perry RH: Consensus guidelines for the clinical and pathologic diagnosis of dementia with Lewy bodies (DLB): report of the Consortium on DLB international workshop. Neurology 1996;47:1113-1124.

3 Perry EK, Haroutunian V, Davis KL, Levy R, Lantos P, Eagger S, Honavar M, Dean A, Griffiths M, McKeith IG, Perry RH: Neocortical cholinergic activities differentiate Lewy body dementia from classical Alzheimer's disease. Neuroreport 1994;5:747-749.

4 Perry EK, Irving D, Kerwin JM, McKeith IG, Thompson P, Collerton D, Fairbairn AF, Ince PG, Morris CM, Cheng AV, Perry RH: Cholinergic transmitter and neurotrophic activities in Lewy body dementia: similarity to Parkinson's and distinction from Alzheimer disease. Alzheimer Dis Assoc Disord 1993;7:69-79.

5 McKeith I, Del Ser T, Spano P, Emre M, Wesnes K, Anand R, Cicin-Sain A, Ferrara R, Spiegel R: Efficacy of rivastigmine in dementia with Lewy bodies: a randomised, double-blind, placebo-controlled international study. Lancet 2000;356:2031-2036.

6 Grace J, Daniel S, Stevens T, Shankar KK, Walker Z, Byrne EJ, Butler S, Wilkinson D, Woolford J, Waite J, McKeith IG: Long-term use of rivastigmine in patients with dementia with Lewy bodies: an open-label trial. Int Psychogeriatr 2001;13:199-205.

7 Thomas AJ, Burn DJ, Rowan EN, Littlewood E, Newby J, Cousins D, Pakrasi S, Richardson J, Sanders J, McKeith IG: A comparison of the efficacy of donepezil in Parkinson's disease with dementia and dementia with Lewy bodies. Int J Geriatr Psychiatry 2005;20:938-944.

8 Mori S, Mori E, Iseki E, Kosaka K: Efficacy and safety of donepezil in patients with dementia with Lewy bodies: preliminary findings from an open-label study. Psychiatry Clin Neurosci 2006;60:190-195.

9 Rowan E, McKeith IG, Saxby BK, O’Brien JT, Burn D, Mosimann U, Newby J, Daniel S, Sanders J, Wesnes K: Effects of donepezil on central processing speed and attentional measures in Parkinson's disease with dementia and dementia with Lewy bodies. Dement Geriatr Cogn Disord 2007;23:161-167.

10 Edwards K, Royall D, Hershey L, Lichter D, Hake A, Farlow M, Pasquier F, Johnson S: Efficacy and safety of galantamine in patients with dementia with Lewy bodies: a 24-week open-label study. Dement Geriatr Cogn Disord 2007;23:401-405.

11 Folstein MF, Folstein SE, McHugh PR: "Mini-mental state". A practical method for grading the cognitive state of patients for the clinician. J Psychiatr Res 1975;12:189-198.

12 Mori E, Ikeda M, Kosaka K; Donepezil-DLB Study Investigators: Donepezil for dementia with Lewy bodies: a randomized, placebo-controlled trial. Ann Neurol 2012;72:41-52.

13 Ikeda M, Mori E, Kosaka K, Iseki E, Hashimoto M, Matsukawa N, Matsuo K, Nakagawa M; Donepezil-DLB Study Investigators: Long-term safety and efficacy of donepezil in patients with dementia with Lewy bodies: results from a 52-week, open-label, multicenter extension study. Dement Geriatr Cogn Disord 2013;36:229-241.

14 Ikeda M, Mori E, Matsuo K, Nakagawa M, Kosaka K: Donepezil for dementia with Lewy bodies: a randomized, placebo-controlled, confirmatory phase III trial. Alzheimers Res Ther 2015;7:4.

15 Mori E, Ikeda M, Nagai R, Matsuo K, Nakagawa M, Kosaka K: Long-term donepezil use for dementia with Lewy bodies: results from an open-label extension of Phase III trial. Alzheimers Res Ther 2015;7:5.

16 Cummings JL: The Neuropsychiatric Inventory: assessing psychopathology in dementia patients. Neurology 1997;48(5 suppl 6):S10-S16.

17 Cummings JL, Mega M, Gray K, Rosenberg-Thompson S, Carusi DA, Gornbein J: The Neuropsychiatric Inventory: comprehensive assessment of psychopathology in dementia. Neurology 1994;44:2308-2314.

18 Hashimoto M, Manabe Y, Mori E, Hirono N, Kosaka K, Ikeda M: Content validity and inter-rater reliability of the Cognitive Fluctuation Inventory (in Japanese). Brain Nerve 2014;66:175-183.

19 Ikeda M, Mori E, Iseki E, Katayama S, Higashi Y, Hashimoto M, Miyagishi H, Nakagawa M, Kosaka K: Adequacy of using consensus guidelines for diagnosis of dementia with Lewy bodies in clinical trials for drug development. Dement Geriatr Cogn Disord 2016;41:55-67.

20 Hoehn MM, Yahr MD: Parkinsonism: onset, progression, and mortality. 1967. Neurology 2001;57(10 suppl 3):S11-S26.

21 Ganguli M, Ratcliff G, Huff FJ, Belle S, Kancel MJ, Fischer L, Kuller LH: Serial sevens versus world backwards: a comparison of the two measures of attention from the MMSE. J Geriatr Psychiatry Neurol 1990;3:203-207.

22 Espino DV, Lichtenstein MJ, Palmer RF, Hazuda HP: Evaluation of the Mini-Mental State Examination's internal consistency in a community-based sample of Mexican-American and European-American elders: results from the San Antonio Longitudinal Study of Aging. J Am Geriatr Soc 2004;52:822-827.

23 Lipkovich I, Dmitrienko A, Denne J, Enas G: Subgroup identification based on differential effect search - a recursive partitioning method for establishing response to treatment in patient subpopulations. Stat Med 2011;30:2601-2621. 
Mori et al.: Pretreatment Cognitive Profile Likely to Benefit from Donepezil Treatment in Dementia with Lewy Bodies: Pooled Analyses of Two Randomized Controlled Trials

24 Lipkovich I, Dmitrienko A: Strategies for identifying predictive biomarkers and subgroups with enhanced treatment effect in clinical trials using SIDES. J Biopharm Stat 2014;24:130-153.

25 Hanyu H, Shimizu S, Hirao K, Kanetaka H, Sakurai H, Iwamoto T, Koizumi K, Abe K: Differentiation of dementia with Lewy bodies from Alzheimer's disease using Mini-Mental State Examination and brain perfusion SPECT. J Neurol Sci 2006;250:97-102.

26 Graff-Radford J, Boeve BF, Pedraza O, Ferman TJ, Przybelski S, Lesnick TG, Vemuri P, Senjem ML, Smith GE, Knopman DS, Lowe V, Jack CR Jr, Petersen RC, Kantarci K: Imaging and acetylcholinesterase inhibitor response in dementia with Lewy bodies. Brain 2012;135(Pt 8):2470-2477.

27 Calderon J, Perry RJ, Erzinclioglu SW, Berrios GE, Dening TR, Hodges JR: Perception, attention, and working memory are disproportionately impaired in dementia with Lewy bodies compared with Alzheimer's disease. J Neurol Neurosurg Psychiatry 2001;70:157-164.

28 Levy R, Eagger S, Griffiths M, Perry E, Honavar M, Dean A, Lantos P: Lewy bodies and response to tacrine in Alzheimer's disease. Lancet 1994;343:176.

29 Cummings JL, Street J, Masterman D, Clark WS: Efficacy of olanzapine in the treatment of psychosis in dementia with Lewy bodies. Dement Geriatr Cogn Disord 2002;13:67-73.

30 McKeith IG, Dickson DW, Lowe J, Emre M, O’Brien JT, Feldman H, Cummings J, Duda JE, Lippa C, Perry EK, Aarsland D, Arai H, Ballard CG, Boeve B, Burn DJ, Costa D, Del Ser T, Dubois B, Galasko D, Gauthier S, Goetz CG, Gomez-Tortosa E, Halliday G, Hansen LA, Hardy J, Iwatsubo T, Kalaria RN, Kaufer D, Kenny RA, Korczyn A, Kosaka K, Lee VM, Lees A, Litvan I, Londos E, Lopez OL, Minoshima S, Mizuno Y, Molina JA, Mukaetova-Ladinska EB, Pasquier F, Perry RH, Schulz JB, TrojanowskiJQ, Yamada M; Consortium on DLB: Diagnosis and management of dementia with Lewy bodies: third report of the DLB Consortium. Neurology 2005;65:1863-1872.

31 Mori E, Ikeda M, Nakai K, Miyagishi H, Nakagawa M, Kosaka K: Increased plasma donepezil concentration improves cognitive function in patients with dementia with Lewy bodies: an exploratory pharmacokinetic/ pharmacodynamic analysis in a phase 3 randomized controlled trial. J Neurol Sci 2016;366:184-190. 